\title{
A Probe into the Legal Interests of the Crime of Infringing on Citizens' Personal Information
}

\author{
Yaqing Wang*, Xuelei Yu \\ Honors College, Nanjing Normal University, Nanjing, China \\ Email address: \\ wang13962657939@163.com (Yaqing Wang),yuxuelei1@126.com (Xuelei Yu) \\ ${ }^{*}$ Corresponding author
}

\section{To cite this article:}

Yaqing Wang, Xuelei Yu. A Probe into the Legal Interests of the Crime of Infringing on Citizens' Personal Information. Advances in Sciences and Humanities. Vol. 5, No. 6, 2019, pp. 160-164. doi: 10.11648/j.ash.20190506.14

Received: September 3, 2019; Accepted: December 23, 2019; Published: December 26, 2019

\begin{abstract}
In the debate on the legal interests of the crime of infringing on citizens' personal information, legal interest is the starting point of judging illegality, so we take the specific legal interest protected by this crime as our first research content. In terms of research methods, our project comprehensively uses various legal research methods, such as article analysis method and document analysis method. Starting from article of law, it closely follows criminal justice cases and judicial practice, analyzes practical problems in combination with legal theory, and forms the research level of article of law - judicial practice - legal theory. The theory of the right to self-determination of citizens' information is the most admissive one because of the constitutional basis and realistic background. The right to self-determination of citizens' information is the right to control your personal information according to law and decide whether it is collected and used. But it will lead to the infinite expansion of the criminal law network, and it is difficult to rationalize the statutory punishment of the crime of infringing on citizens' personal information. In order to control the scope of the criminal law legal network, it is necessary to restrict the right to self-determination of citizen information with "identifiable information." The rationality of the statutory penalty for this crime lies in that this crime has the super-individual legal benefit (the information security and order of the society). To conclude, the crime of infringing on citizens' personal information should have both personal and supra personal legal interests.
\end{abstract}

Keywords: Crime of Infringing on Information, Personal Legal Interest, Super Personal Legal Interest

\section{Question}

$<$ Interpretation on Several Issues Concerning the Application of Laws in the Handling of Criminal Cases of Infringing on Citizens' Personal Information> provides further clarification to the Chinese Criminal Law regarding the Crime of Infringing on Citizens' Personal Information. This Judicial Interpretation is important in that it makes response to the disputes in the practice of legal issues and provides guidance for judicial authorities to accurately combat the crime of Infringing on Citizens' Personal Information. But the interpretation does not answer the current questions concerning the legal benefits of the crime, which is the starting point of the criminal illegality's examination. The fuzziness of the legal benefits of the crime leads to the doubts in the component elements of this crime in judicial judgments, such as, whether the real-name accounts belong to the citizens' personal information. Therefore, it is necessary to clarify the legal benefits of this crime to determine its strike radius.
At present, the discussion on the legal interests of infringing on citizens' personal information mainly focuses on its personal legal interests, but the specific contents of the personal legal interests are still unclear [1]. In addition to personal legal interests, does this crime have the attribute of supra-personal legal interests? What is the content of supra-personal legal interest attribute?

\section{The Exploration of the Property of Personal Legal Interests of the Crime}

\subsection{Theoretical Review}

There is no dispute about the individual attribute of the legal interest of the crime of infringing on citizens' personal information. There are four main views in academia.

The first point of view of personality right says that the legal interest is a citizen's personality right [2]. The main 
reason is that legislators arrange this crime in Chapter IV Crimes of Infringing upon the Rights of the Person and the Democratic Rights of Citizens in the criminal law. However, the arrangement of the criminal law can only reflect the intention of the legislator, and cannot prove the due legal interest of the crime. Secondly, in the era of big data, personal information not only carry the citizen's personality interests, but also is assets with economic value. Nowadays, the acquisition of personal information is the first step to conduct commercial activities. Some of the personal information even have direct economic value, such as third-party payment information, account information of the virtual property. So the legal interest of this crime cannot be limited within the personality right. To say the least, even if the legal interest of this crime belongs to the personality right of an individual, it does not indicate what kind of personality right it belongs to. The protection scope is thus too wide, which is equivalent to the expansion of the criminal law strike circle, and it will also bring confusion to judicial officers.

The second point of view say that the legal interest is the Right to Privacy [3], the theory thinks that the crime is to protect the right of privacy embodied in personal information [4]. This view confuses the definition of personal information with privacy. First of all, citizens' personal information in the context of criminal law is identifiable. According to the interpretation, "citizens' personal information" means all kinds of information recorded in electronic form or any other form, which can be used, independently or in combination with other information, to identify a specific natural person's personal identity or reflect a specific natural person's activities, including the natural person's name, identity certificate number, communication and contact information, address, account password, property status, and whereabouts, among others. By contrast, personal privacy is not identifiable. It is difficult to convince the public that ID card number, communication contact information" in the interpretation can be viewed as privacy. Secondly, personal information can be used to create social wealth; Privacy, however, refers to the information that an individual is not willing to disclose or the information that if disclosed, will cause adverse influence to the individual. The confusion of the protection object will lead to the distortion of the scope of the strike. For example, this crime cannot effectively punish the illegal use of citizens' exposed personal information, so it will make the purpose of this amendment difficult to realize, and it has been criticized by many scholars.

The third point of view is the dual legal interest theory, which holds that the legal interest protected by this crime is citizens' freedom of information, security and privacy. This view also confuses citizens' personal information with privacy [5]. Scholars who hold this view mostly believe that the personal privacy of citizens lacks the protection of criminal law and should be protected by the crime of infringing on citizens' personal information. In fact, this is a kind of intrusion. To protect citizens' personal privacy, a perfect private law protection system should be established, instead of imposing this task on crimes of infringing on citizens' personal

\section{information.}

The fourth point of view says that the legal interest is the right of information self-determination, which refers to the right of individuals to control their personal information in accordance with the law and decide whether to be collected and used. It is based on the general right of personality, so the right to self-determination of information should belong to the right of personality. The elaboration of the right of personality theory indicates that the right of personality protected by the crime of violating citizens' personal information is citizens' right of information self-determination. This view has increasingly become the general theory in the academic circle, and has been advocated by many scholars.

\subsection{Reflection on the Right to Self-determination of Information}

Among the four theories, information self-determination is the most admissible one. First, the right to information self-determination belongs to constitutional legal interests. Through the logical argumentation and text deduction of the current constitution text, the right of information self-determination belongs to the basic right of constitution. Article 38 of the current constitution clearly stipulates that "the personal dignity of citizens of the People's Republic of China is inviolable". According to the general theory of constitutional science, the right of name, portrait, reputation, honor and privacy can be deduced from the personal dignity stipulated in this article, and the right of information self-determination is a new specific right of personality protected by the constitution in our country [6]. The human rights clause in article 33 of the constitution also has enough space to accommodate the right of information self-determination [7]. Second, the trait of this crime is that illegally obtaining, sell or provide information about individual citizens under the condition of citizens not knowing, therefore the direct infringement is the right to control the flow of their personal information, that is the personal information right to self-determination.

But there is something wrong with it. First, in the theory of self-determination of information, the right to self-determination of personal information lies in all steps of personal information processing and all personal information. Its classic expression is: "an individual can decide to whom to tell what information related to him or to withhold what information". This right applies to all personal information, including inessential personal information [8]. Therefore this view will enlarge the scope of protection and limit the final use of personal information space. In fact, citizens' personal information should be used properly to create the largest social wealth and fully promote efficiency. A good law should draw a safe zone of the utilization of citizens' personal information to prevent citizens' personal information from being abused, instead of forbidding the reasonable collection, mining and analysis of personal information. Secondly, the right of information self-determination cannot explain the rationality of the punishment of this crime. In terms of the horizontal comparison of penalties, the maximum legal penalty for the 
crime of insulting, defamation, infringement of the freedom of communication, and the crime of opening, concealing, destroying mail and telegraphy without permission is only three years, while the maximum legal penalty for the crime of infringing on the personal information of citizens is seven years [9]. In terms of the longitudinal comparison of penalties, the legal punishment of the crime of infringement of citizens' personal information is even harsher than the crimes which are aim to protect the upper right to life of the law protection, such as the crime of causing death. If one commits the crime of causing death, he will be sentenced to fixed-term imprisonment of more than three years but not more than seven years. If the circumstances are relatively light, he shall be sentenced to fixed-term imprisonment of not more than three years. A crime that infringes on personal information alone can carry the same maximum sentence as a crime that infringes on the right to life and the minimum sentence of the latter is even lower than the former. Therefore, no matter in horizontal or vertical comparison, if the legal interest protected by the crime of infringing on citizens' personal information is only the right to self-determination of personal information, the punishment allocation is unreasonable and uncoordinated.

Therefore, the right to self-determination of information has infinitely expanded the scope of criminal law, and it is difficult to explain the rationality of legal punishment for the crime of infringing on citizens' personal information in the criminal law penalty system. It is necessary to reconstruct the theory of self-determination of information to solve the above problems and prevent the criminal law from illegalizing normal and reasonable use of citizens' personal information.

\subsection{The Reconstruction of the Theory of Self-determination of Information}

In order to avoid the expansion of the scope of criminal law, a standard should be established to limit the scope of citizens' personal information. The question then boils down to what criteria can limit the scope of citizen information?

In order to find out the answer, we should return to the original purpose of the legislation. Released by the standing committee of the National People's Congress: "In recent years, leaks of citizens' personal information have occurred from time to time, posing a serious threat to citizens' personal, property and privacy, said a draft statement on the amendment to the criminal law". It can be seen that the legislature added and amended this crime several times to take this crime as a tool to prevent telecom fraud, Internet fraud and nuisance soft violence crimes and other downstream crimes. In this way, the legislator put up a warning sign ahead of schedule to prevent the threat to citizen's person and property posed by information leakage. Secondly, the interpretation rules that "knew or should have known that others use of committing crimes citizens personal information, to sell or provide", "illegal acquisition, sell or provide whereabouts trajectory information, being used for crime" are serious circumstances. It can also be a disproof of this above proposition.

Only information that can correspond to specific people, that is, information with "identifiability", can have personal attributes and economic attributes, and its disclosure will strike the personal and property interests of the leaked subject accurately, so it is necessary for the criminal law to protect it. Information that cannot point to specific person does not produce the corresponding social harmfulness. Therefore, the legal interest protected by the crime of infringing on citizens' personal information should be citizens' right to self-determination of identifying information.

\section{The Identification of the Extra-personal Legal Interest Attribute of the Crime}

\subsection{The Existence of Extra-personal Legal Interests Attribute of the Crime of Infringing on Citizens' Personal Information is Reasonable}

However, identifiable information is only the refinement of citizens' personal information, which is not superior to citizens' personal information. Therefore, it still can not explain the rationality of the penalty of the crime of infringing on citizens' personal information. Then, does this crime have other types of legal interests?

The determination of legal interests needs to trace back to the characteristics of the criminal object itself. In the Big Data era, personal information has a tendency to transcend individuality and become public. With the development of data mining technology and the change of information content, the disclosure of personal information can affect the whole characteristics of a citizen and thus form the whole portrait of a citizen. Furthermore, because personal information is often aggregated, a data packet leak will often lead to a large number of personal information leakage, which infringing billions of personal information and making the social information order unstable. So it is of great concern to public security.

Secondly, this crime also presents the public characteristic in every link of crime - legislation - judicature. First of all, the actor usually does not take the information of specific citizens as the target, but attaches importance to the type and amount of information obtained in the industrial chain of personal information crime, which shows the characteristics of non-specific and majority. In the illegal information underground trading, the information is mostly sold in units of number., Rather than the identity of the information owner, the information is mostly sold on the basis of the information type. Second, in the constitution of this crime, the amount of citizens' personal information violated is an important threshold for incrimination. Based on the importance of different types of personal information, the interpretation sets more than 50, more than 500 and more than 5,000 incrimination standards respectively, so as to realize the compatibility of guilt and punishment. Third, hundreds of personal information and thousands of RMB of illegal gains become "essential facts" in almost every case in the trial 
practice [10]. Moreover, judging from the content of the violated information, the punishment for this crime is generally not a criminal act that violates certain personal information, but an act that violates a certain kind of information of many citizens [11].

To sum up, the legal interests infringed by this kind of crime have a considerable degree of publicity, and thus possess the attribute of supra-personal legal interests. Because of this, the rationality of the penalty can proved.

\subsection{The Verification of the Extra-personal Legal Interests Attribute of the Crime of Infringing on Citizens' Personal Information}

Then, what is the specific content of the supra-personal legal interest of the crime of infringing on citizens' personal information?

From the practical background of the overall legislation, personal information, as the gold of the information age, should be circulated in a reasonable and legal way to promote the development of commercial society in the modern information society [12]. The illegal acquisition and circulation of information is a breakthrough to the normal order of the information society, which turns personal information from the development resource of the commercial society into the basic tool of crime, which poses a threat to the information security and cases impacts the personal rights and property of citizens [13]. Because of this, the criminal law as a tool of social norms, should face up to the seriousness of this harmful result and intervene before the actual harmful result to maintain and promote the order and security of the information society [14].

In terms of the specific crime of infringing on citizens' personal information, the overall information order of the society can be considered as the collection of each individual's information security [15]. When the social information order is destroyed, every individual in the information society will face the risk of information disclosure, and their right of information self-determination will be threatened by infringement at any time. Moreover, information disclosure is likely to produce a domino effect, which will eventually lead to personal and property security damage. Therefore, the overall information order of the society is related to the information security of every citizen in the society [16].

Therefore, it should be considered that the legal interest of citizens' personal information crime is the order and security of the information society. As the barrier of citizens' information self-determination right, it is to protect micro interests in a macro way under the risk society.

\section{Conclusion}

To clarify the legal interests of the crime of infringing on citizens' personal information is the logical starting point to understand this crime [17]. The crime of infringing on citizens' personal information should have both personal legal interests and extra-personal legal interests [18]. In the discussion about the personal legal benefits of this crime, the theory of citizen's information voluntary right is the most admissible. However, such a view will lead to the unlimited expansion of the criminal law network, and it is difficult to rationalize the statutory punishment for the crime of infringing on citizens' personal information. In order to control the scope of criminal law, it is necessary to reconstruct the right to self-determination of citizens' information. The rationality of the legal punishment for the crime of infringing on citizens' personal information lies in the information security and information order of the information society.

\section{References}

[1] Fan fei. Considerations on legal interests of criminal law in risk society [J]. Journal of shandong police college, 2016, 28 (04): 63-69.

[2] PI yong, wang suzhi. Legal benefits and harmful behaviors of the crime of infringing on personal information in the context of big data $[\mathrm{J}]$. Journal of hainan university (humanities and social sciences edition), 2017, 35 (05): 114-124.

[3] Wang zhaowu, xiao kai. Some problems in the identification of crimes against citizens' personal information [J]. Law, 2009 (12): 146-155.

[4] CAI jun. Rational analysis on legislation of personal information infringement crime -- and reflection and prospect on the legislation of this crime [J]. Modern law, 2010, 32 (04): $105-112$.

[5] See zhou guangquan, theories on criminal law (3rd edition), 2016 edition of renmin university of China press, pages 71 and 72; Chen xingliang, Ed.: criminal law (3rd edition), fudan university press, 2016, page 256.

[6] Jing lijia. The legal benefits of the crime of infringing on citizens' personal information in the context of big data $[\mathrm{J}]$. Law review, 2008, 36 (02): 116-127.

[7] Yao yuerong. Evidence of information self-determination as a basic right in China [J]. Politics and law, 2012 (04): 72-83.

[8] Yang fang. Theory of self-determination of personal information and its review -- on the protection object of personal information protection law $[\mathrm{J}]$. Comparative law research, 2015 (06): 22-33.

[9] Jiang haiyang. Advocating the crime of infringing on citizens' personal information beyond personal legal interests [J]. Jiao tong university law, 2018 (03): 139-155.

[10] J. dowiree Dodd, Data Security law-state Statutory Requirements for Protecting Personal Data, American Journal of Trial Advocacy, Vol. 38, 2015, p. 623.

[11] Ge Yue-ying. Information Security and Privacy Protection of Citizens in Big Data Era: An Interview with the Deputy Director of the Policy and Law Committee of the China Electronic Commerce Association. Information China. 2014.

[12] Wang Xia. Security Management and Maintenance Analysis of Computer Network in Government Agencies. Electronics World. 2017.

[13] Liu Ming-xiao. Typical Cases of Crimes of Infringing Citizens' Personal Information. Procuratorial Daily. 2017. 
[14] Office of the Central Leading Group for Cyberspace Affairs. Ministry of Public Security: The National Public Security Organs Conducted a Total of 1886 Cases of Infringement of Personal Information of Citizens Last Year. http://www.cac.gov.cn/2017-03/11/c1120608963.htm. 2017.

[15] Feng Gailin. On personal information protection law and criminal law [J]. Society, 2016, (32): 178-179.

[16] Zhang Libo. Study on the criminal law protection of personal information of citizens. [J]. legal science Expo, 2015, (26): 265 .
[17] Li Li. The perfection of criminal law on network data security and personal information protection of citizens [J]. Journal of China University of Political Science and Law, 2015, (04): 64-78+159.

[18] Yun-Feng Wu. On the Judicial Application of Crime of Infringing Citizens' Personal Information-From the Perspective of Network Security Law [J]. Journal of Henan Police College, 2017. 